\title{
Biological controls in botanic gardens
}

\author{
Julian Ives ${ }^{1}$
}

\section{Abstract}

Biological control of insect pests in horticulture is evolving rapidly but use in botanic gardens can be difficult due to the variety and extent of the plant collections held at these gardens. This paper describes examples of successful biological control of mealybug species at the Cambridge University Botanic Garden and Royal Botanic Garden Edinburgh and looks at some of the challenges to extending the use of such controls in all environments.

\section{History of biological control}

The history of biological control has origins deep in the past but was relatively slow to develop as a mainstream form of insect pest control until quite recent times. There are some interesting examples of natural enemies being used to control insect pests by the Chinese in the 3rd century (Legner \& Goeden, 1987). The ant Oecophylla smaragdina was sold for the control of citrus insect pests, and Erasmus Darwin discusses the use of parasitoids in 1800 to control cabbage caterpillars (Darwin, 1800). There was a surge in biological control activity before World War II but the development of cheaper synthetic insecticides after the war suppressed its use and development.

There were significant developments in the use of biological control in the late 1980s and 1990s for growers of crops and plants under glass in Western Europe. Several factors were behind this:

1. The costs of renewing registrations of existing synthetic chemical insecticides and of launching new formulations increased significantly, which led to fewer products being available to growers.
2. Supermarkets introduced minimum and zero levels of pesticide residues on produce supplied by growers.

3. The growth of environmental and organic pressure groups raised consumer awareness of the dangers of pesticide use.

4. The widespread introduction of bumblebees to pollinate crops such as tomatoes restricted insecticide applications.

These factors combined to force growers to produce and grow crops in a different way. This was welcomed by the majority, because resistance to insecticide in pests was increasing and the health benefits were obvious for the grower and consumers. This has led to the widespread use of beneficial insects for insect pest control by greenhouse growers of produce such as tomatoes, peppers and cucumbers, and an increase in the range available (Fig. 1). The amenity sector, which includes botanic gardens, is increasingly considering the use of biological controls (also known as bio-controls) to deal with pests.

\footnotetext{
1 Julian Ives is Director of Dragonfli Ltd, a company which sells biological controls and advises on their use. Address: Dragonfli Ltd, 4 Rippers Court, Sible Hedingham, CO9 3PY, UK. 


\section{Biological controls offer an opportunity for botanic gardens}

Botanic gardens and their mixed and extensive plant collections can harbour many different insect pests (Fig. 1). This poses a greater challenge than pest control in a monoculture crop, where crops can be cleared out, all plant material taken away and the empty glasshouses cleaned. This is rarely possible in the case of a valuable and fixed botanic garden collection. Insect pest populations are often provided with the ideal conditions for their development with no practical way of removing them. The effectiveness of insecticide decreases with overuse and the problem is compounded with a limited range from which to choose. It can also be difficult to apply these insecticides without closing areas to visitors or damaging other life in the area, such as fish in ponds (Fig. 2). Many botanic gardens, including Cambridge University Botanic Garden and the Royal Botanic Garden Edinburgh (RBGE), are working towards a zero-use policy of neonicotinoid-based insecticides. This is because certain research (Gibbons et al., 2015) indicates that neonicotinoids are harmful to bees and other beneficial insects.

The benefits of adopting this approach are numerous: not only does plant health improve without insecticide use but humans benefit too. Insects also build up resistance to insecticides the more they are applied, so they become less effective with continued use. Insecticides can harm pollinating insects and naturally occurring beneficial insects such as ladybirds. Therefore, it is not sensible or efficient to base insect pest control programmes purely on insecticides. Another advantage of implementing a biological control programme at botanic gardens includes creating an added visitor attraction. Many visitors are genuinely interested in the use of beneficial insects for pest control and they approve of its environmentally friendly credentials.

Sometimes botanic gardens fail to capitalise on this positive public relations

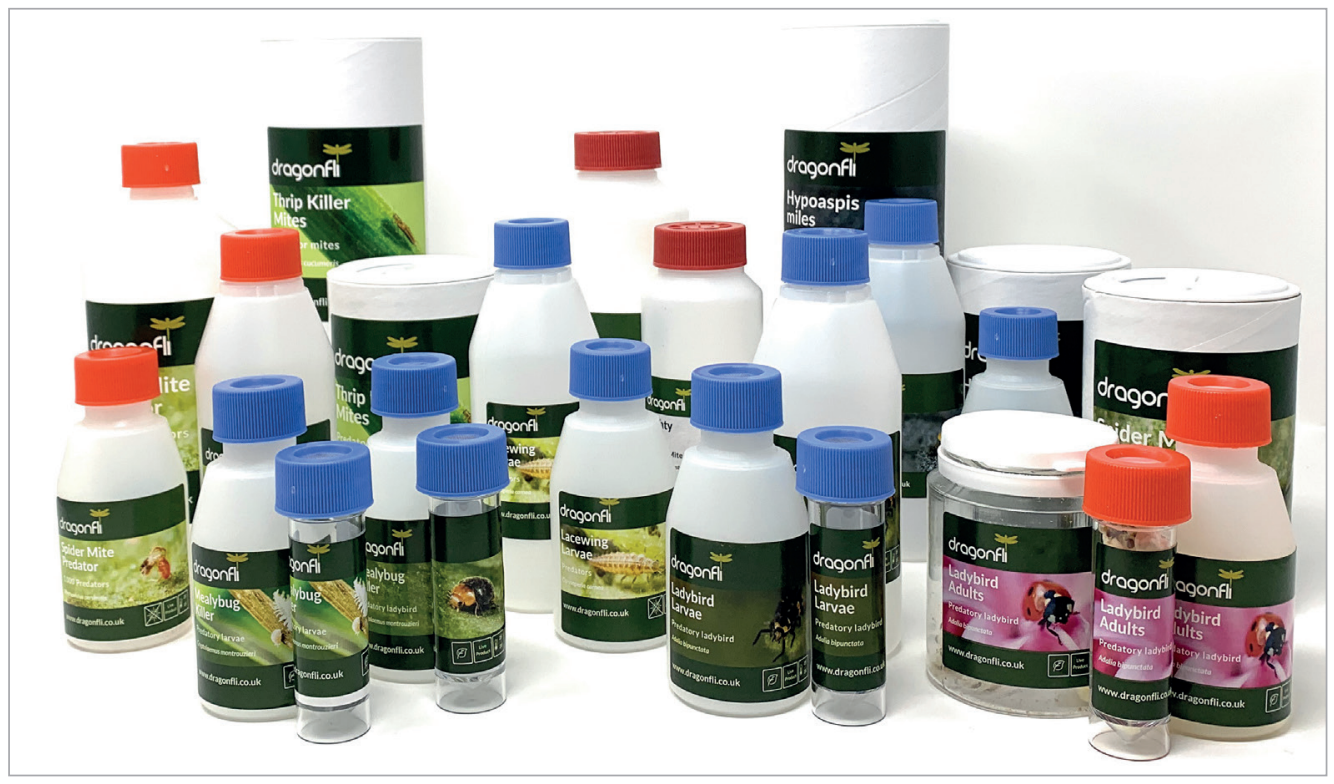

Fig. 1 A selection of assorted bio-controls ready for application. These are all ready for release. Photo: Dragonfli. 


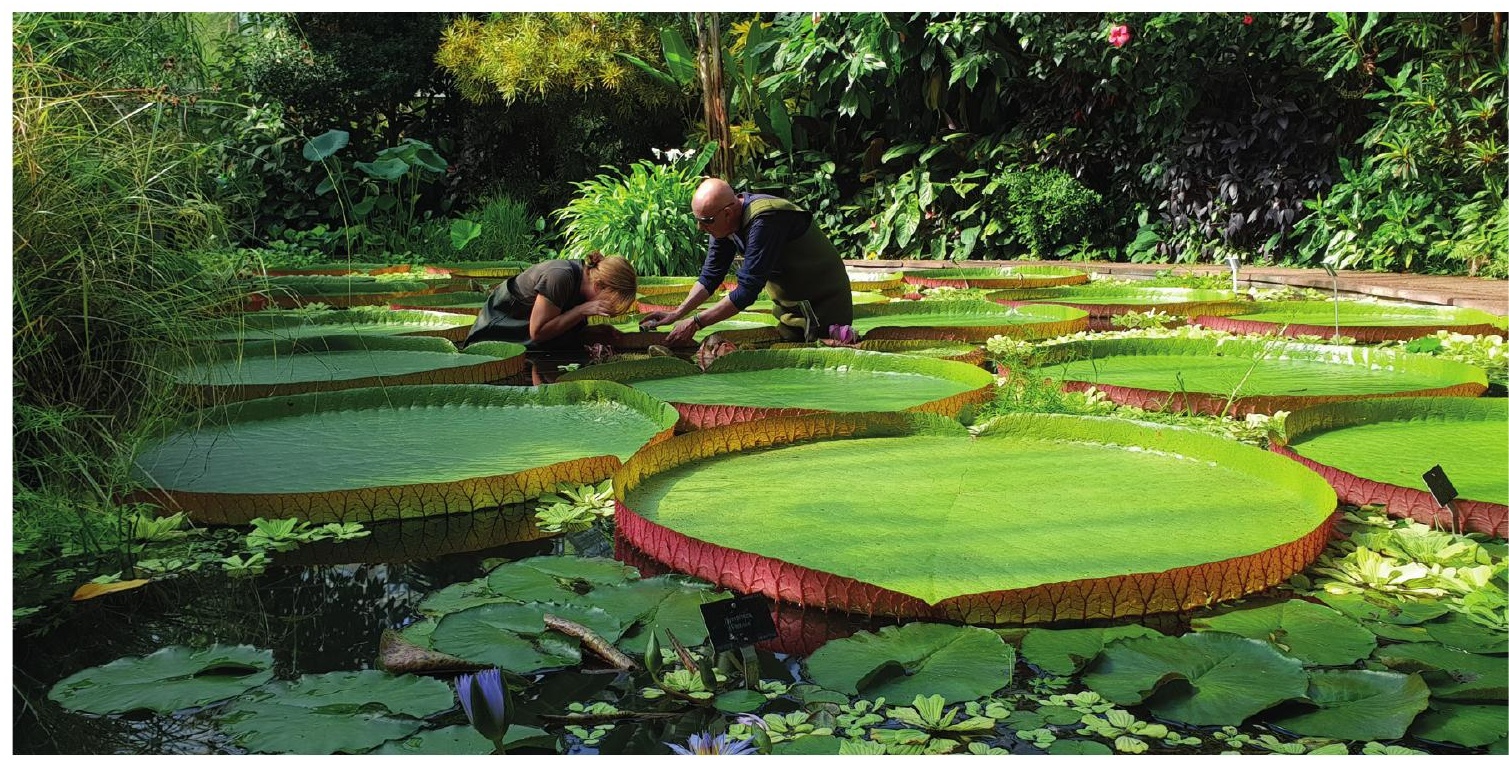

Fig. 2 Victoria amazonica varieties (Victoria lilies) in the Tropical Aquatic House at the Royal Botanic Garden Edinburgh provide the perfect host plant for several aphid species. Here the bio-control product APHISCOUT, developed by Koppert Biological Systems, is being applied. This product is a mix of parasitic wasps and provides a good solution to control of aphids where the use of chemicals is not recommended. Photo: Cameron Tasker.

exercise. Signage explaining which beneficial insects are used and how they are used can add interest and value to the visitor experience. However, the most important reason for using biological control is its effectiveness at controlling insect pests. That is not to say that it is easy; there are many challenges to overcome when implementing an effective biological control programme.

\section{Steps towards the use of biological control in botanic gardens}

The first step is to identify the insect pests present. Correct identification is essential as it is important to introduce the correct natural enemy to combat the pest. This can be difficult. Some insect pests that are present are not native to the UK but have established in plant collections here. This can mean that the natural enemy to that insect is either not available or not permitted for importation and use against these pests.
Legislation should provide protection against the introduction of non-native insects; however, the system in both England and Scotland has not been updated along with the decrease in use of chemicals and increase in bio-control research. The system needs to be reviewed in order to enable a quicker assessment of whether a non-native beneficial insect can be safely introduced in protected environments to combat non-native pests which are already established in these environments.

Once the insect pest has been identified, a bespoke biological control can be devised that will take into consideration the pests on site and the conditions into which they will be introduced. It is important to introduce beneficial insects where the conditions are right for them to operate effectively. If it is too cold or too wet, many won't be active - or even survive - and if the light levels are not correct some will not reproduce. Biological control can be expensive and so 
appropriate assessment of the conditions is essential to maximise resources. Every site is different, and no one blueprint programme can be rolled out, so it takes time to adapt a programme that works well in the conditions. This is done by keeping records of where and when introductions have been made, which helps to build a picture of the conditions in order to maximise the timing of introductions. However, every year is different in terms of weather and environmental conditions, so growers have to be prepared to be flexible in adjusting biological programmes to counter fresh pest infestations as they occur.

Monitoring and scouting of pest and beneficial insect populations is also very important. Early observation of pests is essential to prevent populations getting out of balance, so training in identification and appropriate allocation of staff to the task can have a big impact on the success of biological control programmes. Some publications, such as Malais \& Ravensberg (1992) and Helyer et al. (2003), provide helpful information on insect life cycles for pests and their natural enemies, and can be used by staff to improve their knowledge. The internet can also be a useful source of information for identifying pests and their natural enemies; the RHS website, for example, is a good resource. ${ }^{2}$

A relatively new recommendation for success with the use of bio-controls at botanic gardens is to use the method of mass introduction of beneficial insects at targeted times. For many years, the traditional approach for introductions of beneficial insects was to introduce small numbers at intervals over the summer period. These introductions were often not targeted, and the same introductions in the same small quantities were made year after year. This often led to disappointing results with inadequate control of some insect pests. Cambridge University Botanic Garden pioneered a new approach followed by RBGE, where large applications of beneficial insects are made at key times in order to overrun the insect pests, rather than trickling in small numbers over longer periods. An example of the effectiveness of this is given in the case study below which discusses the control of mealybugs on plant collections kept under glass.

\section{Case study: biological control of two species of mealybug with Cryptolaemus montrouzieri}

It is common to find several species of mealybug in botanic garden collections. At Cambridge University Botanic Garden and RBGE, there are at least two, including Planococcus citri (citrus mealybug) and Pseudococcus longispinus (longtailed mealybug) (Fig. 3). These sap-sucking pests extract large amounts of sap and produce a honeydew which drips down onto other plants. This honeydew then grows a black mould, which is unsightly and reduces the photosynthetic capacity of plants affected when there are large numbers of mealybugs present. Plants are weakened by the sap extraction, and also by the horticultural process of regular cleaning and cutting of infected leaves. Carrying out this cleaning and cutting is also especially challenging when the mealybugs are high up in the canopy of a tree or large plant.

The most commonly used beneficial insect to control mealybugs is a beetle in the ladybird family, Cryptolaemus

\footnotetext{
${ }^{2}$ https://www.rhs.org.uk
} 
montrouzieri (Fig. 3). This was first used as a biological control of citrus mealybug in California (Bartlett \& Lloyd, 1958). Both the larva and adult stages of its life cycle feed on mealybugs. The young larvae feed on mealybug eggs and the older larvae and adults feed on all stages of the mealybug (Fig. 4). The older larvae are the most voracious, consuming up to 30 mealybugs a day. The optimum condition for their population growth is $22-25^{\circ} \mathrm{C}$ with a relative humidity of 70-80 per cent. The beetle will not develop at temperatures under $14{ }^{\circ} \mathrm{C}$.

These predators can control mealybugs, but it is not always straightforward, especially in a botanic garden environment. Mealybugs are very adept at hiding during the winter months, often in the structure of greenhouses or in the plant collections. Given that the plant collections are often mature and fixed

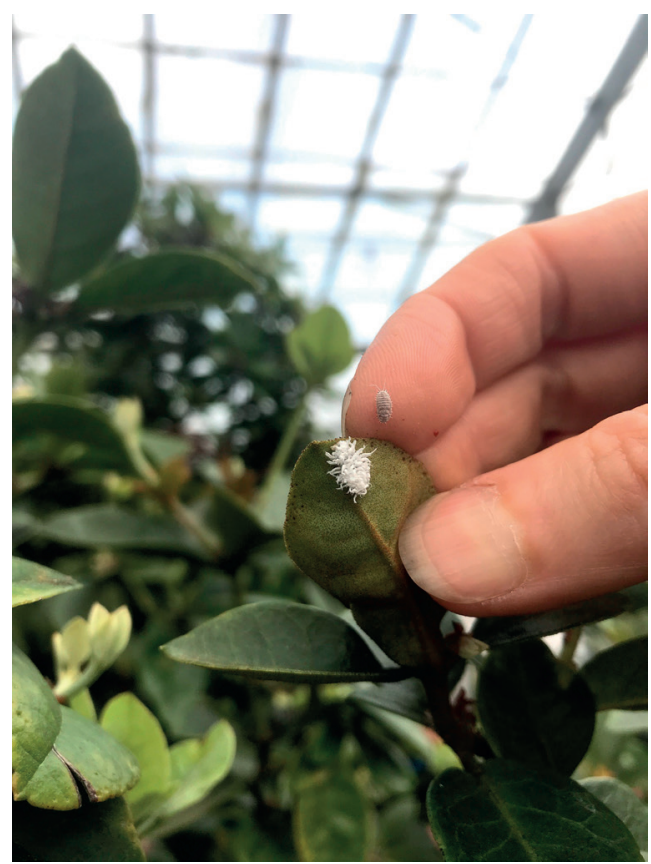

Fig. 3 Bio-control insect and pest. On the leaf is the larva of Cryptolaemus montrouzieri. On the finger is the adult female of Pseudococcus viburni (obscure mealybug). Photo: Paulina Maciejewska-Daruk.

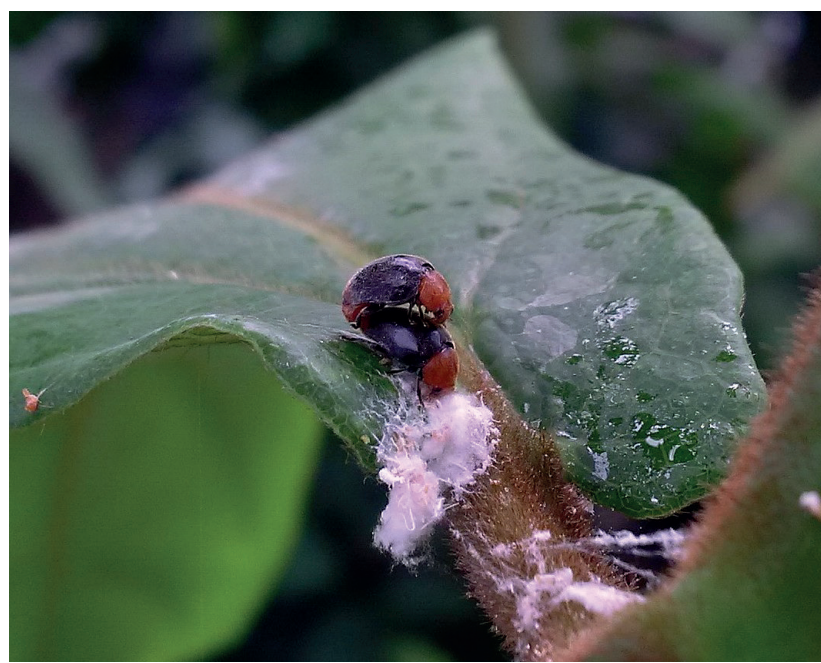

Fig. 4 Adult Cryptolaemus montrouzieri mating and feeding on egg sacs of Planococcus citri. Photo: Paulina Maciejewska-Daruk.

for many years, the hiding places become larger and access to them to remove the mealybugs becomes more difficult as time passes. The longtailed mealybug will hide in and around flower buds and quickly becomes more active as temperatures rise, often before the conditions are suitable for releasing Cryptolaemus predators. Longtailed mealybugs are also viviparous, which means that no eggs are produced, just live young. The eggs of mealybugs are the part of the life cycle that the Cryptolaemus like to eat most, and this often leads to other mealybug species being consumed first, leaving a population of the longtailed mealybug. Other species of mealybug also have parasitic wasps that can be released to supplement control of them when combined with the Cryptolaemus so the longtailed mealybug is the most difficult to control. The longtailed mealybug has one commercially available parasite but, being a non-native species, its use in the UK is currently prohibited.

These factors led to a rethink at Cambridge University Botanic Garden and 
RBGE about how many Cryptolaemus should be introduced when attempting to combat the longtailed mealybug. The traditional way of releasing low numbers of adult beetles at intervals over the summer had proved to be ineffective. At the same time, producers of bio-controls have become more efficient at producing large numbers of Cryptolaemus, enabling the larval form of the life cycle to be more readily available. This has resulted in larger unit sizes, which means large numbers of Cryptolaemus larvae can be purchased and applied directly onto the mealybug larvae. This is further aided by the use of small distribution boxes that the larvae can be placed in and hung in the plant canopy, and therefore distributed more evenly throughout the population (Fig. 5). By being placed close to the mealybugs, the Cryptolaemus

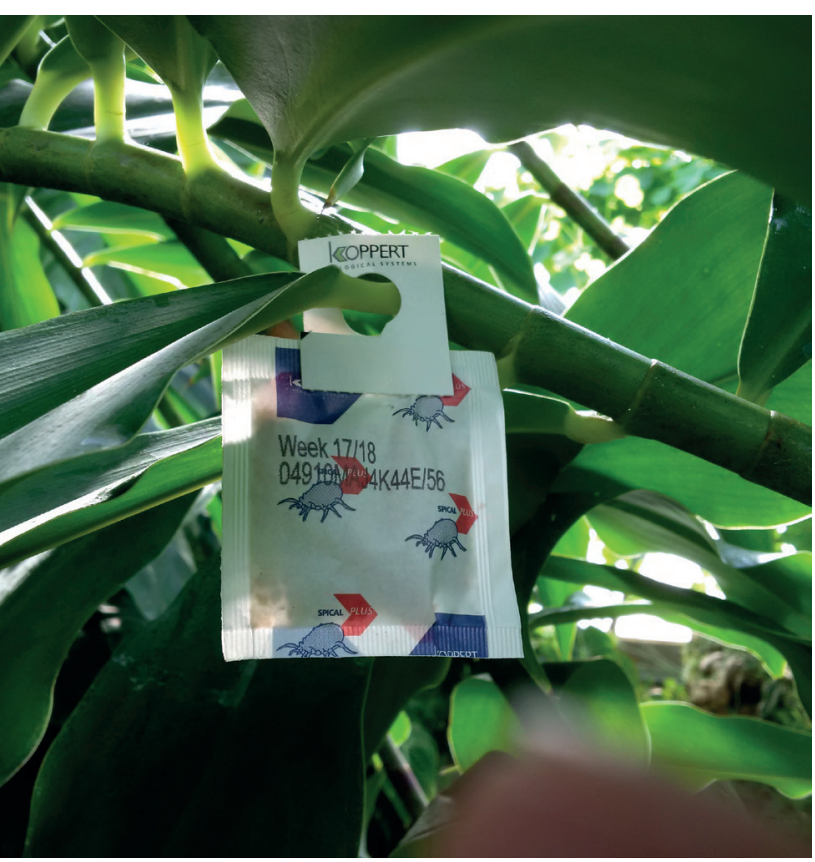

Fig. 5 Bio-controls are put into the plant canopy by hanging slow-release sachets of the predatory insect on plants. This one contains Amblyseius californicus which will control red spider mites. Photo: Paulina Maciejewska-Daruk. larvae are able to attack quickly and in large numbers. By using the voracious larval part of the Cryptolaemus life cycle, the mealybug is more effectively targeted. The larvae will also complete their life cycle on the plant, resulting in the production of adults, which are then able to search for further mealybug populations on which to feed.

Temperature has a dramatic impact on the development time of Cryptolaemus populations, as shown by Table 1 (reproduced from Malais \& Ravensberg (1992), table 9.2, p. 221).

This relatively long life cycle at the lower end of the temperature table is another reason why it is important to introduce large numbers of larvae in single applications and not rely on staggered small introductions. The large release of larvae can almost be viewed as a biological insecticide designed to take out large numbers of mealybugs.

It is difficult to predict how many largescale introductions will be required in one season, as this will depend on the size of the mealybug population, the species present and the climatic conditions in the glasshouse. Large-scale infestations of mealybugs, especially when dealing with longtailed mealybugs, may require two or three applications of Cryptolaemus per year. It can also take several years to significantly reduce mealybug numbers but once this strategy has been implemented the results

\begin{tabular}{|c|c|}
\hline Temperature $\left({ }^{\circ} \mathbf{C}\right)$ & Generation time (days) \\
\hline 18 & 72 \\
\hline 21 & 54 \\
\hline 27 & 33 \\
\hline 30 & 25 \\
\hline
\end{tabular}

Table 1 The egg-to-egg development of Cryptolaemus montrouzieri at different temperatures. 
can be impressive. This has been the case at Cambridge University Botanic Garden and at RBGE. The initial cost of these mass introductions can test pest control budgets compared to smaller introductions. However, the overall gain in better pest control is viewed by those responsible for collection management and adopting this strategy as a price worth paying. At sites where the mass release strategy is deployed overall costs start to go down in years two and three, as fewer mass introductions are required due to the significantly lower number of mealybugs.

\section{Traditional and new biological controls available to growers}

Mass releases are not the answer for all insect pests; some do require regular releases of small numbers of beneficial insects. One example of this is Encarsia formosa for the control of whitefly. This tiny little parasitic wasp is one of the oldest and longest-used biological control agents. Regular releases every few weeks during the summer months provide a tried-and-tested form of whitefly control.

A more modern development in biological control is the use of breeder sachets for predatory mites. These sachets were first developed to aid the control of thrip populations in cucumber crops. The predatory mite Amblyseius cucumeris (or Neoseiulus cucumeris) is mixed with a common prey mite that feeds on bran. The Amblyseius feeds on the bran mite and reproduces in the sachet; as the bran mite population is eaten this forces the ever-increasing population of Amblyseius out of the sachet and onto the plants where the sachets are hung. These sachets can produce predatory mites for over four weeks. This has provided the first effective biological control of thrips in cucumber crops. Since its development in 1992, the breeder sachet is now used for several predatory mite species including two that feed on red spider mite: Amblyseius californicus (or Neoseiulus californicus) and A. andersoni. These sachets are valuable assets for botanic gardens because they provide a preventative form of control for the two-spotted spider mite Tetranychus urticae (Fig. 5). The slow-release sachets can be hung on plants before the spider mite arrives which means that the predators are already on the plants when the first spider mites emerge from their winter diapause. Both these predators can also feed on pollen, which helps them survive on plants when no spider mite is present. The use of these predatory mites provides a significant improvement in spider mite control on plant collections.

Other new predators are also joining the biological control armoury, some with an appetite for numerous insect pests. One that has been trialled at RBGE and is proving to be very successful is Amblyseius montdorensis. This predatory mite feeds on both whitefly eggs and thrip larvae. It can also tolerate low and high temperatures. At RBGE and Cambridge, it is a useful early biological control for whitefly eggs when the temperatures are too low for Encarsia formosa.

\section{Biological controls outdoors}

Biological control is evolving quickly for plants grown under glass. Some pests, such as scale insects, are still a challenge due to a lack of control insects; however, solutions for most insect pests can be found. The next challenge for the industry is when biological control needs to move outdoors. Here the environments are more 
difficult to manage. The threats from native and new non-native pests are a cause for concern. Turf pests such as the native chafer grubs and leatherjackets cause extensive damage to parks and gardens. This is due partly to changing climate conditions and partly to the removal of long-used insecticides. The bio-control solution has been to use nematodes over large areas of grassland. The results of these applications are variable especially when there are very high numbers of larvae present in the soil beneath the turf. The key to success is irrigation, as the nematodes need moisture in the soil in order to find the larvae and move to infect them. The very dry conditions of summer 2018 provided a challenging climate for these large-scale applications of nematodes.

The arrival in the UK of some non-native pests is alarming, not only because of the damage they cause, but also the speed of their spread. One example is Cameraria ohridella (horse chestnut leafminer). This tiny moth has spread throughout the UK within a few years, causing significant damage to Aeschylus castanea (horse chestnut) and changing their appearance dramatically. No effective strategy has been devised to control this pest, probably because of the low commercial value of the trees. The most effective way to reduce numbers of this moth is by destroying the leaf litter when it has dropped, as many pupae are in the leaves and removal of these helps to reduce the extent of future infestations.

A more recent invader is Cydalima perspectalis (box tree moth). This invasive pest has caused significant damage to many high-profile gardens in France including Versailles. The moth lays eggs that develop into caterpillars and can completely kill Buxus plants, so much so that historic collections of box hedges and plants are already threatened. The pest is widespread in southern England and is spreading northwards fast. It can tolerate low temperatures and so is unlikely to be deterred by harsher climates. Dragonfli is collaborating with the Royal Horticultural Society at Hyde Hall to trial nematodes combined with moth trapping using pheromone to combat this pest. The likelihood of more non-native invasive insects arriving and establishing in gardens and glasshouses is high.

\section{Conclusion}

Biological control methods need to evolve and adapt as there are new pests in a changing environment. Botanic gardens provide the ideal conditions for pests and beneficial insects alike. Each garden has a unique mixture of plants, which create challenging scenarios where insect pests can develop quickly in a climate perfectly suited to them. There are few textbooks and guidelines on how to deploy the best biological control programme because every site is unique. For this reason, bespoke programmes have to be developed for each site. New methods and sometimes new beneficial insects must be tried to counter new and longstanding insect pests. The benefits of using bio-controls are numerous: healthier plants, healthier staff and a chemical-free environment that is good for everyone. For plants, this means healthier growth without the application of pesticides; for staff there are no harmful side-effects from contact with pesticides and no residues left in the environment to potentially harm visitors. Biological control is interesting to the visitor and can add to the already positive experience of visiting botanic gardens. 


\section{Acknowledgements}

Many thanks to the horticulture staff at Cambridge University Botanic Garden and RBGE. Especial thanks go to Alex Summers, Glasshouse Supervisor at Cambridge, Louise Galloway, Glasshouse Supervisor at RBGE, and Pat Clifford, Senior Horticulturist at RBGE, for contributing to the case study described here. Thanks also to Cameron Tasker, Horticulturist at RBGE, for providing Fig. 2.

\section{References}

BARTLETT, B.R. \& LLOYD, D.C. (1958). Mealybugs attacking citrus in California - a survey of their natural enemies and the release of new parasites and predators. Journal of Economic Entomology, 51: 90-93.

DARWIN, E. (1800). Phytologia; or: The philosophy of agriculture and gardening. With the theory of draining morasses and with an improved construction of the drill plough. J. Johnson, London.

GIBBONS, D., MORRISSEY, C. \& MINEAU, P. (2015). $A$ review of the direct and indirect effects of neonicotinoids and fipronil on vertebrate wildlife. Environmental Science and Pollution Research, 22(1): 103-118. Available online: https://doi.org/10.1007/ s11356-014-3180-5 (accessed July 2019).

HELYER, N., BROWN, K. \& CATTLIN, N.D. (2003). A Colour Handbook of Biological Control in Plant Protection. Royal Horticultural Society/Manson, London.

LEGNER, E.F. \& GOEDEN, R.D. (1987). Larval parasitism of Rhagoletis completa (Diptera: Tephritidae) on Juglans microcarpa (Juglandaceae) in western Texas and southeastern New Mexico. Proceedings of the Entomological Society of Washington, 89: 739-743.

MALAIS, M.H. \& RAVENSBERG, W.J. (1992). Knowing and Recognizing Biological Control. Koppert B.V., AD Berkel en Rodenrijs. 